\title{
Endowing Virtual Characters with Expressive Conversational Skills
}

\author{
Marilyn A. Walker \\ University of California, Santa Cruz, Ca. 95060, U.S.A. \\ mawalker@ucsc.edu
}

Keywords: Dialogue, Conversation, Personality, Affective Generation.

\section{Introduction}

When humans interact with one another, socially intelligent conversational behaviors arise from the interaction of a number of different factors: the conversants' personality, cultural knowledge, the ability to observe and reason about social relationships, and the ability to project and detect affective cues. For virtual agents to be socially intelligent, they must have an expressive conversational repertoire. Moreover, scientific progress in this area requires that these expressive capabilities be easily parameterized, to support experimentation, and that at least some of the factors mentioned above be used to control the parameters. In this talk, I describe our research on expressive spoken language generation, and discuss how our work aims for both psychological plausibility and realistic usability. To achieve psychological plausibility we build on theories and detailed studies of human language use, such as the Big Five theory of personality, and Brown and Levinsons theory of politeness $[1|2| 3$. To achieve realistic usability, we have developed both rule-based and trainable generation methods that can dynamically, and in real time, change an agents linguistic style by modifying the values of these theoretically motivated parameters. This will allow us to experiment with dynamically modifying an agent's linguistic style based on theories of audience design, entrainment and alignment.

We built the first generator based on B\&L as part of the VIVA virtual theatre, an application for teaching English as a second language [1. We recently extended these ideas in the PoLLy system [4, and evaluated human perceptions of the politeness variations that PoLLy can generate, and how these vary across cultures and discourse contexts, encoding relevant factors. See Table 1 .

Our work on personality is embodied in PERSONAGE one of the first parameterizable generators based on the Big Five theory, which provides 67 different parameters, controlling utterance length and polarity, lexical, syntactic and pragmatic choice, and rhetorical structure. See Table 2. PERsonage's parameters are all motivated by previous corpus-based studies on the linguistic reflexes of personality. Our evaluation experiments show that humans recognize utterances as manifesting the personality that the agent intended. 
Table 1. Example outputs of PoLly for Politeness Strategies, with average ratings of human judges on politeness perceptions, on a scale from 1 to 5 , with $1=$ rude and 5 $=$ over-polite, when the utterance was spoken to a Friend $(\mathbf{F})$ or a Stranger $(\mathbf{S})$

\begin{tabular}{|l|l|l|l|}
\hline Strategy & Possible Utterances & F & S \\
\hline \hline Direct & $\begin{array}{l}\text { Chop the onions, Please chop the onions, You could chop the } \\
\text { onions. You must chop the onions. }\end{array}$ & 2.3 & 1.8 \\
\hline Approval & $\begin{array}{l}\text { Could you please chop the onions. If you don't mind you can } \\
\text { chop the onions. }\end{array}$ & $\begin{array}{l}\text { Would it be possible for you to chop the onions. I'm sure you } \\
\text { wouldn't mind chopping the onions. Could you possibly chop } \\
\text { the onions for me. I know I'm asking you for a big favor but } \\
\text { could you please chop the onions. I'm wondering whether it } \\
\text { would be possible for you to chop the onions. Would you not } \\
\text { like to chop the onions. }\end{array}$ & 2.8 \\
\hline Indirect & $\begin{array}{l}\text { The onions aren't chopped yet. The onions should have been } \\
\text { chopped. Someone should have chopped the onions. Someone } \\
\text { has not chopped the onions yet. }\end{array}$ & 2.0 & 1.7 \\
\hline
\end{tabular}

Table 2. Example outputs of Personage for Extraversion, Emotional Stability and Agreeableness Traits, with perceptual ratings of human judges, on a scale of 1 to 7, with $1=$ very low (e.g. introvert) and $7=$ very high (e.g. extravert)

\begin{tabular}{|c|c|c|c|}
\hline Trait & Params & Utterance & Rating \\
\hline \multirow[t]{2}{*}{ Extraversion } & low & Chimichurri Grill isn't as bad as the others. & $\overline{1.00}$ \\
\hline & high & $\begin{array}{l}\text { I am sure you would like Chimichurri Grill, you know. The } \\
\text { food is kind of good, the food is tasty, it has nice servers, } \\
\text { it's in Midtown West and it's a Latin American place. Its } \\
\text { price is around } 41 \text { dollars, even if the atmosphere is poor. }\end{array}$ & 6.33 \\
\hline \multirow[t]{2}{*}{ Emotional stability } & low & $\begin{array}{l}\text { I am not sure! I mean, Ch-Chimichurri Grill is the only } \\
\text { place I would recommend. It's a Latin American place. } \\
\text { Err... its price is... it's damn ex-expensive, but it pr-pr- } \\
\text { provides like, adequate food, though. It offers bad atmo- } \\
\text { sphere, even if it features nice waiters. }\end{array}$ & 4.00 \\
\hline & high & $\begin{array}{l}\text { Let's see what we can find on Chimichurri Grill. Basically, } \\
\text { it's the best. }\end{array}$ & 6.00 \\
\hline \multirow[t]{2}{*}{ Agreeableness } & low & $\begin{array}{l}\text { I mean, Chimichurri Grill isn't as bad as the others. Basi- } \\
\text { cally, the staff isn't nasty. Actually, its price is } 41 \text { dollars. } \\
\text { It's damn costly. }\end{array}$ & 2.00 \\
\hline & high & $\begin{array}{l}\text { You want to know more about Chimichurri Grill? I guess } \\
\text { you would like it buddy because this restaurant, which is } \\
\text { in Midtown West, is a Latin American place with rather } \\
\text { nice food and quite nice waiters, you know, okay? }\end{array}$ & 5.75 \\
\hline
\end{tabular}

\section{References}

1. Walker, M.A., Cahn, J.E., Whittaker, S.J.: Improvising linguistic style: Social and affective bases for agent personality. In: Proceedings of the 1st Conference on $\mathrm{Au}-$ tomous Agents, AGENTS 1997, pp. 96-105 (1997)

2. Gupta, S., Walker, M.A., Romano, D.M.: How rude are you?: Evaluating politeness and affect in interaction. In: Proceedings of ACII, pp. 203-217 (2007)

3. Mairesse, F., Walker, M.A.: Trainable generation of Big-Five personality styles through data-driven parameter estimation. In: Proceedings of the 46th Annual Meeting of the Association for Computational Linguistics, ACL (2008)

4. Gupta, S., Walker, M.A., Romano, D.M.: Polly: A conversational system that uses a shared, representation to generate action and social language. In: IJCNLP 2008, The Third International Joint Conference on Natural Language Processing, pp. 203-217 (2008) 